\title{
A educação ambiental para a agricultura familiar e as influências do agronegócio: aproximações entre Brasil e Moçambique
}

Environmental education for family farmers and the influences of agribusiness: approaches between Brazil and Mozambique

\section{La educación ambiental para agricultores familiares y las influencias del agronegocio: enfoques entre Brasil y Mozambique}

Inny Bello ACCIOLY ${ }^{1}$

\section{RESUMO}

Este trabalho é fruto da análise do Programa de Educação Ambiental e Agricultura Familiar (PEAAF), que foi elaborado pelo Ministério do Meio Ambiente do Brasil a partir de reivindicações de movimentos de trabalhadores rurais organizados. Ao examinar um programa educacional específico, buscamos apontar o modus operandi da atual "democracia" brasileira e suas relações com o modelo de desenvolvimento adotado, baseado principalmente na exploração intensiva dos recursos naturais. Reivindicado pelos movimentos dos trabalhadores rurais, o programa analisado rapidamente tornou-se operatório ao padrão de acumulação vigente, especialmente ao definir certo tipo de uso do solo e ao subsumir os conceitos de "agricultura camponesa" e "soberania alimentar" aos conceitos de "agricultura familiar" e "segurança alimentar", por meio de uma "pedagogia da participação". Neste trabalho, também buscamos apontar indícios de que este modelo educacional vem sendo exportado para Moçambique por meio de acordo de cooperação internacional que visa a implantar o Prosavana.

Palavras-chave: educação ambiental; agroindústria; segurança alimentar e nutricional.

\section{ABSTRACT}

This work is the result of the analysis of the Environmental Education and Family Agriculture Program (PEAAF), which was developed by the Ministry of Environment of Brazil from claims of rural workers movements. By examining a specific educational program, we seek to point out the 1 Doutoranda em Educação e Mestre em Educação pela Universidade Federal do Rio de Janeiro. Especialista em Educação Ambiental pela PUC-Rio. Graduada em Educação Artística pela Universidade Federal do Estado do Rio de Janeiro (UNIRIO). Endereço: Faculdade de Educação da Universidade Federal do Rio de Janeiro Avenida Pasteur 250 fundos, sala 234. Rio de Janeiro -RJ - CEP:22290-902 - Campus da Praia Vermelha. Contato: innyaccioly@hotmail. com 
modus operandi of the current Brazilian "democracy" and its relationship with the development model adopted, mainly based on intensive exploitation of natural resources. Claimed by the rural workers movements, the program quickly became operative for the current pattern of accumulation, especially when define a certain way of use the land and when subsume the concepts of "peasant agriculture" and "food sovereignty" to the concepts of "family farming" and "food security" by means of a "pedagogy of participation". In this paper, we also seek to point out evidences that this educational model has been exported to Mozambique through international cooperation agreement called Prosavana.

Keywords: environmental education; agribusiness; food security.

\section{RESUMEN}

Este trabajo es el resultado del análisis del Programa de Educación Ambiental y Agricultura Familiar (PEAAF), que fue preparado por el Ministerio de Medio Ambiente de Brasil a partir de las demandas de los movimientos de trabajadores rurales organizados. Mediante el examen de un programa educativo específico, se busca señalar la forma de la actual "democracia" brasileña y su relación con el modelo de desarrollo adoptado, basado principalmente en la explotación intensiva de los recursos naturales. Reclamado por los movimientos de los trabajadores del campo, el programa se convirtió rápidamente operativo al actual patrón de acumulación, sobre todo por definir cierto tipo de uso del suelo y subsumir el concepto de "agricultura campesina" y "soberanía alimentaria" a los conceptos de "agricultura familiar" y "seguridad alimentaria", todo por medio de una "pedagogía de la participación". En este trabajo, también buscamos señalar evidencias de que este modelo educativo ha sido exportado a Mozambique a través de acuerdo de cooperación internacional dirigido a la implementación de Prosavana.

Palabras clave: educación ambiental; agroindustria; seguridad alimentaria.

\section{INTRODUÇÃO}

Este trabalho tem como objetivo promover o debate acerca de políticas educacionais voltadas para o meio rural. Ao examinar um programa educacional específico, o Programa de Educação Ambiental e Agricultura Familiar (PEAAF), buscamos investigar o modus operandi da atual "democracia" brasileira e seus mecanismos de construção de consensos, assim como apontar recentes iniciativas de exportação destes mecanismos para Moçambique. Nesse sentido, ressaltamos que o campo da Educação vem sendo historicamente disputado como importante ferramenta de convencimento e construção de falsos consensos.

Dessa forma, optamos por iniciar contextualizando o setor agrícola brasileiro na economia mundial, apontando o peso do chamado "agronegócio" no total das exportações e no Produto Interno Bruto (PIB) nacional. Em seguida, abordaremos o papel destinado à agricultura familiar 
neste cenário, assim como as lutas camponesas contra a mercantilização do direito humano à alimentação. Apontaremos, também, as atuais relações entre o governo brasileiro e os empresários do agronegócio.

A partir destas contextualizações, apresentaremos os resultados da análise de um programa educacional promovido pelo governo brasileiro e voltado para o público da agricultura familiar, o Programa de Educação Ambiental e Agricultura Familiar(PEAAF), que foi elaborado pelo Ministério do Meio Ambiente a partir de reivindicações de movimentos de trabalhadores rurais organizados durante o Grito da Terra 2009. Inicialmente reivindicado por movimentos de trabalhadores rurais como um programa educacional que atendesse aos seus interesses de classe, o PEAAF rapidamente tornou-se operatório ao padrão de acumulação vigente ao promover o discurso da parceria - sempre subordinada - entre pequeno agricultor e empresário do agronegócio, de forma que seja fortalecido o uso mercantil da terra e dos demais recursos naturais e as consequentes expropriações deste processo. Por fim, apontamos o programa Prosavana, fruto de acordo de cooperação técnica entre os governos do Brasil, Japão e Moçambique, que vem sendo denunciado por movimentos sociais de Moçambique e do Brasil por promover, na região de Nacala - Moçambique, a apropriação de terras por corporações transnacionais, o que contribuiria para a expropriação de pequenos agricultores moçambicanos e o surgimento da figura do agricultor sem-terra em Moçambique.

\section{O SETOR AGRÍCOLA BRASILEIRO NA ECONOMIA MUNDIAL}

De acordo com o estudo da Organização para Cooperação e Desenvolvimento Econômico $(\mathrm{OCDE})^{1}$, o Brasil é uma das maiores economias mundiais, com um PIB de 2.475 bilhões de dólares, o que lhe valeu a posição de sexta economia mundial em 2011. Nos últimos anos, o Brasil tornou-se um país de rendimentos médios altos, com um PIB per capita de mais de 11.000 dólares por ano, graças a um forte crescimento que registrou a média de 3,6\% entre 2005 e 2012.

Todavia, a desigualdade em matéria de rendimentos continua a ser alta, com um coeficiente $\mathrm{Gini}^{2}$ de 0,55 e $11 \%$ da população vivendo com menos de 2 dólares por dia.

Segundo informações divulgadas no site do Ministério da Agricultura Brasileiro ${ }^{3}$, o país apresenta índices de desenvolvimento agrícola acima da média mundial e lidera a produtividade agrícola na América Latina e Caribe. O agronegócio representa mais de $22 \%$ do Produto Interno Bruto (PIB) brasileiro, que representa a soma de todas as riquezas produzidas.

Um dos principais conceitos de agronegócio é creditado a Davis e Goldberg ${ }^{4}$, que o definiram como a soma total das operações de produção e distribuição de suprimentos agrícolas; as operações de produção nas unidades agrícolas; e o armazenamento, o processamento e a distribuição dos produtos agrícolas, e itens produzidos com eles. Esta interpretação consiste numa perspectiva sistêmica, na qual a agropecuária é visualizada como o núcleo de um sistema econômico que se denominou Complexo Agroindustrial (CAI). Tal núcleo é interligado com setores a montante, responsáveis 
pelo provimento de insumos e de máquinas e implementos para a produção agropecuária, e com setores a jusante, responsáveis pelo processamento, pela transformação da produção agropecuária (agroindústria) e pela distribuição (comercialização, armazenagem e transporte) das produções agropecuária e agroindustrial, além de outros serviços associados ao agronegócio.

No Brasil, a Associação Brasileira do Agronegócio (ABAG), criada em 1993, tem no seu quadro de entidades associadas ${ }^{5}$ os principais bancos brasileiros, a maior rede de telecomunicações nacional, empresas públicas e corporações transnacionais.

A Figura 1 demonstra o peso que os bens primários - associados às atividades do agronegócio e demais atividades extrativistas - ganharam no total das exportações brasileiras na última década, assim como a redução das exportações de produtos manufaturados.

Figura 1-Exportação Brasileira por Fator Agregado.

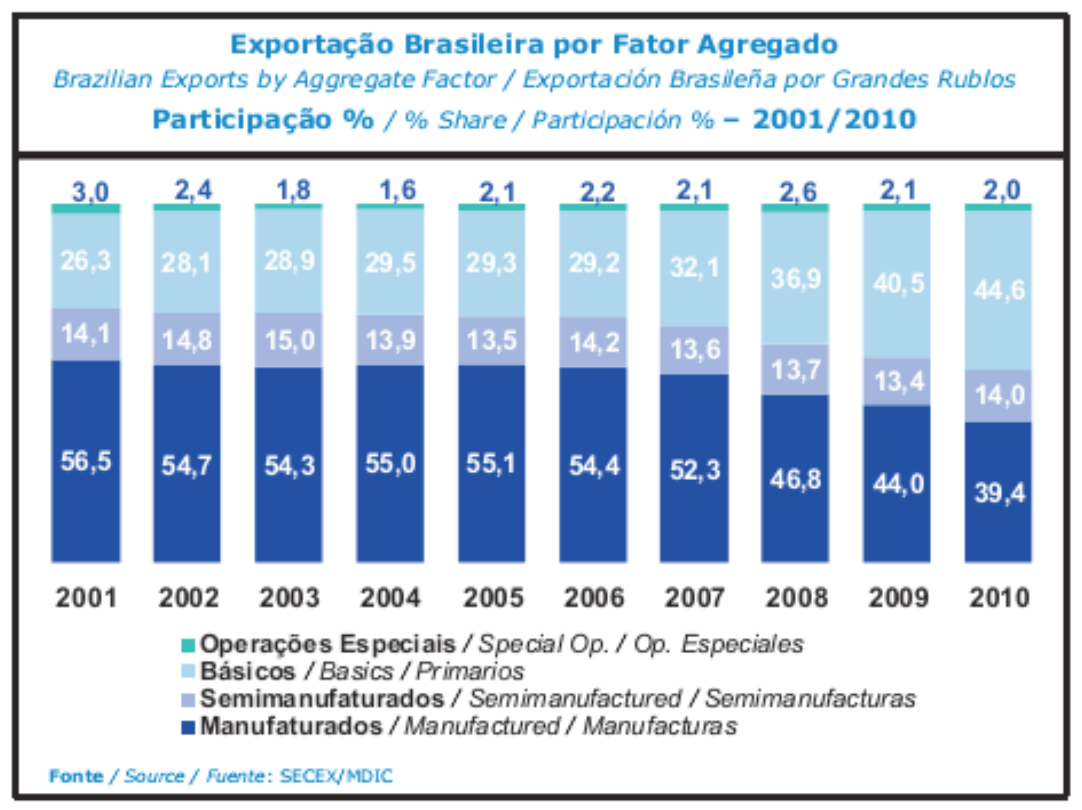

Fonte: Ministério do Desenvolvimento, Indústria e Comércio Exterior (2011) ${ }^{6}$. 
A Figura 2 aponta os mercados de Ásia, América Latina e Europa como os maiores compradores dos produtos brasileiros.

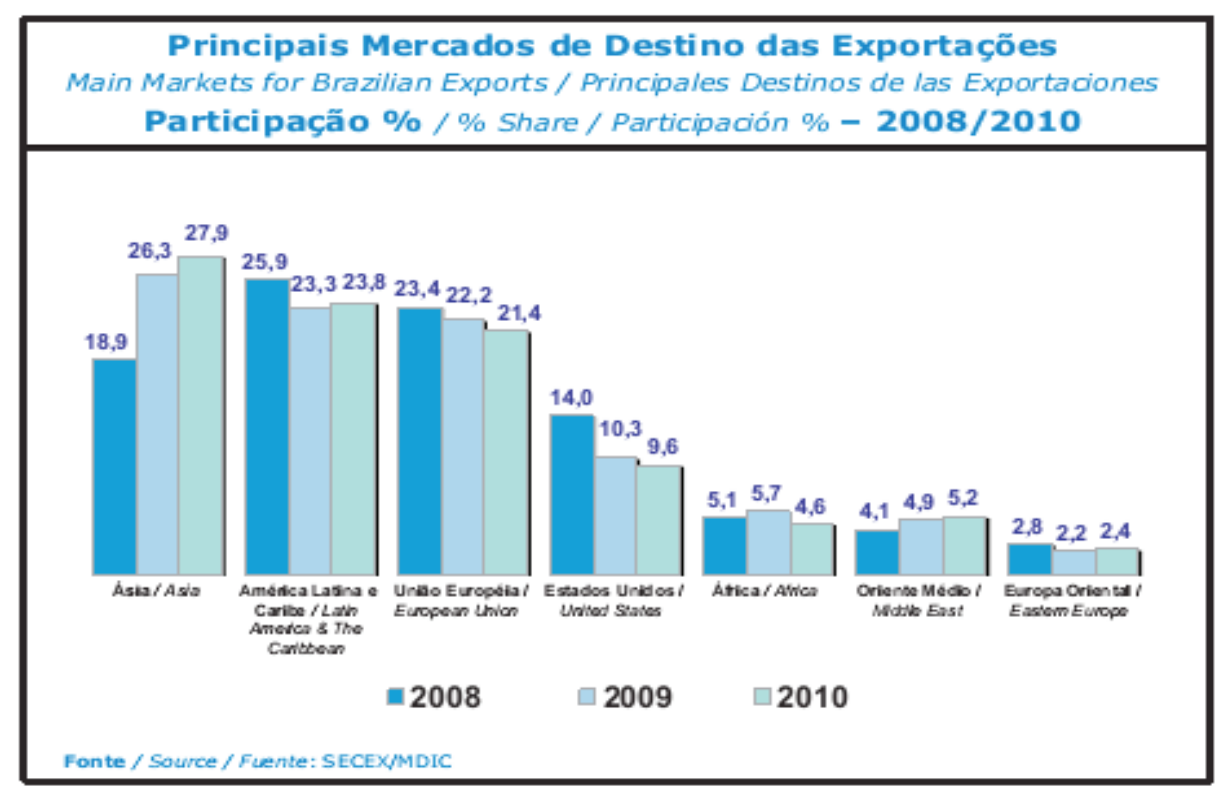

Fonte: Ministério do Desenvolvimento, Indústria e Comércio Exterior (2011) .

Na Tabela 1, são apresentados os produtos que mais cresceram na produção industrial brasileira nos anos de 2009 e 2010: aço (processado a partir da extração do minério de ferro), automóveis (montagem), celulose (a partir da derrubada de árvores de eucalipto), petróleo e papel. Estes setores foram os que mais se destacaram em investigações ${ }^{6}$ acerca dos financiadores das campanhas eleitorais dos parlamentares integrantes das Comissões de Meio Ambiente da Câmara dos Deputados e do Senado Federal em 2010 e 2011, o que pode ser um importante indicador das relações entre financiamento privado de campanhas eleitorais e expansão de determinados setores produtivos que, talvez, ainda tenham contado com incentivos estatais para esta expansão.

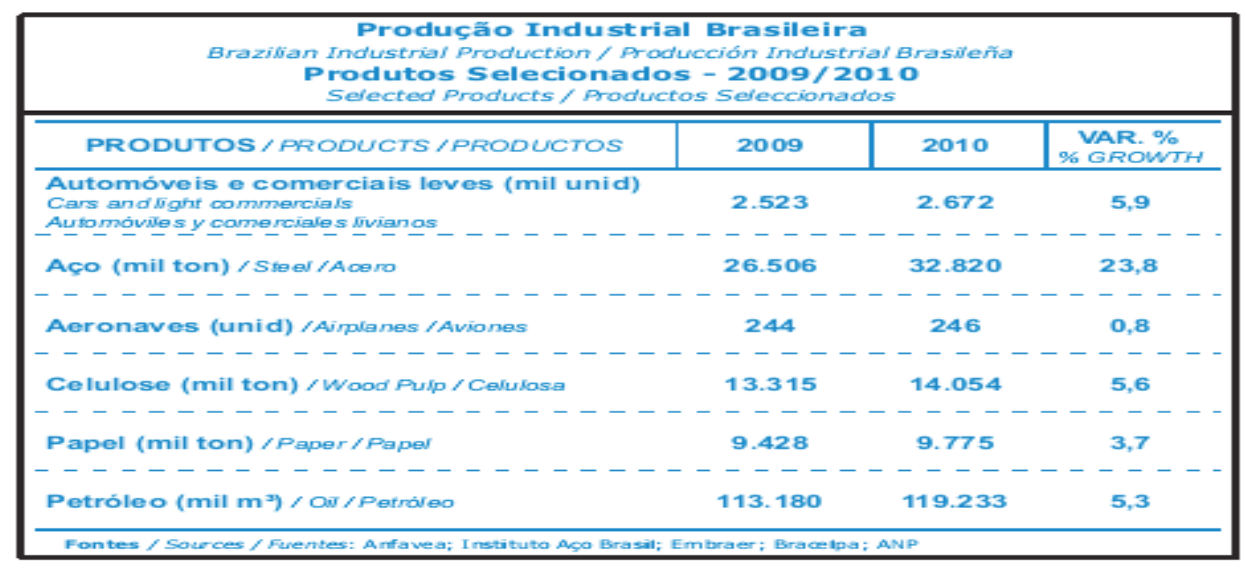

Fonte: Ministério do Desenvolvimento, Indústria e Comércio Exterior (2011) . 
A Tabela 2 apresenta a posição que o Brasil assume no total das exportações mundiais de produtos agrícolas.

\begin{tabular}{|c|c|c|}
\hline $\begin{array}{c}\text { PRODUTOS } \\
\text { PRODUCTS / FFODUCTOS }\end{array}$ & 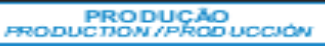 & $\begin{array}{c}\text { EXPORTACAO } \\
\text { EXPORTS/EXPGTACIDN }\end{array}$ \\
\hline AÇOCAAR / SUGAR / AZULAAR & $1^{\circ}$ & $1^{\circ}$ \\
\hline CAFE /COFFEE & $1^{\circ}$ & $1^{\circ}$ \\
\hline 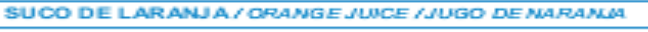 & $1^{\circ}$ & $1^{\circ}$ \\
\hline ETANOL /ETHAMVLL & $2^{\circ}$ & $1^{\circ}$ \\
\hline CARNE BOVINA / BEEF /CARUEE & $2^{\circ}$ & $1^{\circ}$ \\
\hline FUMO/TOEACCO /HLMO & $2^{\circ}$ & $1^{\circ}$ \\
\hline SOUAEM GRĀO / SORBEANS/GRANOS DE SOUA & $2^{\circ}$ & $\mathbf{2}^{\mathbf{\infty}}$ \\
\hline COUROS E PELES / LEATHER AND FUR / CUEROS Y PIELES & $2^{\circ}$ & $\varphi^{\circ}$ \\
\hline CARNE DE FRANGO / CHUCKEN MEAT /POLLO & $3^{\circ}$ & $1^{\circ}$ \\
\hline MINÉFAO DE FERRO / NRONORE / MUNUERAL DE HURRO & $3^{\circ}$ & $2^{\circ}$ \\
\hline CALCAADOS/SHOES/CALZADOS & $3^{\circ}$ & $\sigma^{\circ}$ \\
\hline OLEO DE SOUA/SOTEEAN OW /ACEJTE DESOUA & $4^{\circ}$ & $\mathbf{z}^{\infty}$ \\
\hline FARELO DE SOUA/SO VBEAN FESIDLE / HAFUMA DE SOUA & $4^{\circ}$ & $\mathbf{2}^{\infty}$ \\
\hline MIL HO /MANZE /MAIZZ & $4^{\circ}$ & $3^{\circ}$ \\
\hline AMOOES / AUPPLAMES / AVMONES & $4^{\circ}$ & 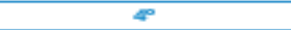 \\
\hline CARNE SUINA /PORK MEAT/CAFUE DE CERDO & $4^{\circ}$ & \pm \\
\hline ALGODĀO /COTTCON/ALGCOONN & $5^{\circ}$ & $5^{\circ}$ \\
\hline AUTOMÓVEUS / CARS/ALTONOOWUES & $5^{\circ}$ & $12^{\circ}$ \\
\hline 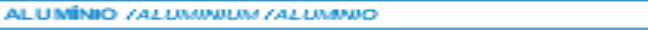 & $7^{\circ}$ & $\sigma^{\circ}$ \\
\hline ACYO/STEEL /ACERO & $9^{\circ}$ & $13^{\circ}$ \\
\hline
\end{tabular}

Fonte: Ministério do Desenvolvimento, Indústria e Comércio Exterior (2011) .

Apesar do papel assumido pelo Brasil como uma "potência agrícola", a população brasileira sofre com a forte variação dos preços dos alimentos. O IPCA (Índice de Preços ao Consumidor Amplo), criado com o objetivo de oferecer a variação dos preços no comércio para o público final e medido mensalmente pelo Instituto Brasileiro de Geografia e Estatística (IBGE), apontou (conforme gráfico a seguir) que, de janeiro de 2011 a maio de 2013, a variação dos preços dos alimentos foi maior que a variação de preços dos produtos em geral. É preciso considerar que, segundo informações do $\mathrm{IBGE}^{7}$, a alimentação detém a maior parcela do orçamento mensal das famílias $(23,93 \%)$.

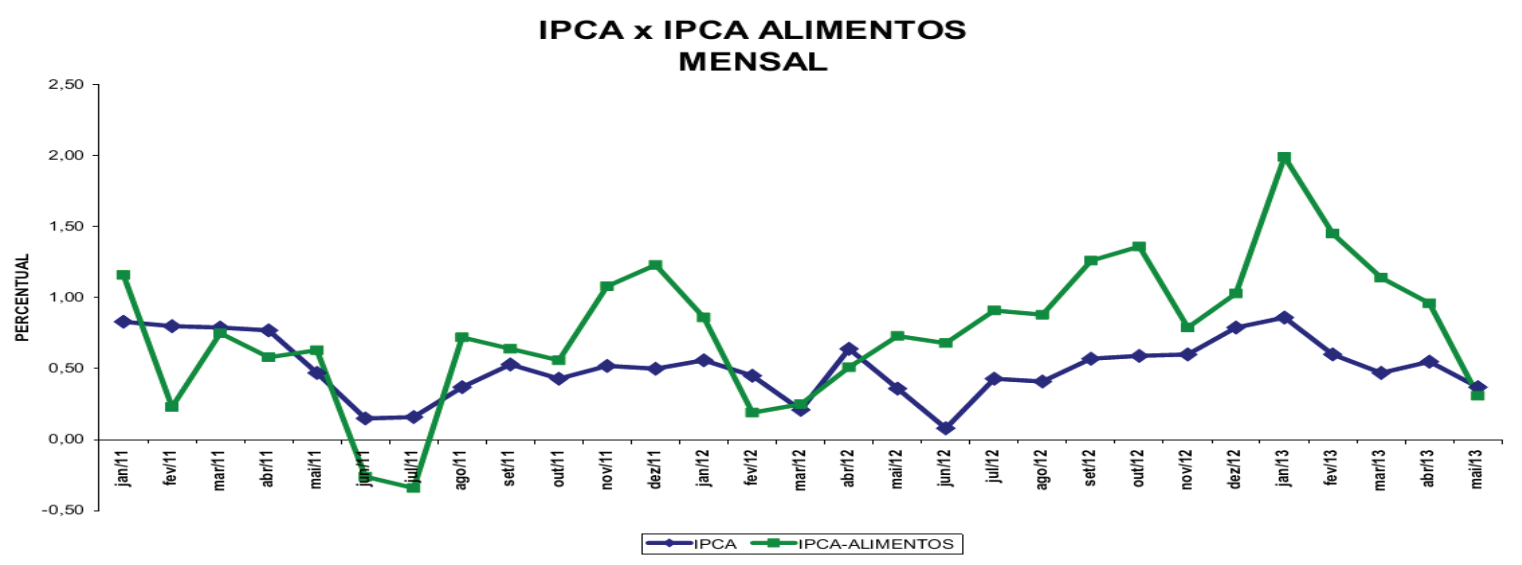

Fonte: Ministério da Agricultura, Pecuária e Abastecimento. Secretaria de Política Agrícola. Departamento de Economia Agrícola. Coordenação Geral de Análises Econômicas. (2013) 
Estatísticas e dados básicos de economia agrícola.

É um tanto paradoxal que, no mesmo período em que um padrão econômico voltado para os mercados externos está em curso e atinge importantes realizações, os salários e as condições gerais de trabalho e de vida da maioria da população da América Latina assistam à drástica precarização. Não se consegue evitá-la apesar das políticas sociais levadas a cabo por alguns Estados ou do crescimento significativo alcançado por algumas economias. [...] Para essa nova modalidade de reprodução o mercado dos assalariados locais não constitui um elemento de maior relevância à medida que parte substancial da produção vai destinada aos mercados externos.[...] Em segundo lugar, a capacidade de concorrência desse padrão nos mercados externos reside na deterioração dos salários locais e na depreciação de tudo o que implique elevar os custos do trabalho, como benefícios sociais diversos ${ }^{8}$.

A consolidação, no Brasil, do padrão exportador de especialização produtiva ${ }^{9}$, baseado no fortalecimento do modelo produtivo do agronegócio produtor de commodities agrícolas para exportação, somado ao intenso grau de articulação política deste setor no Congresso Nacional e sua forte influência sobre o atual governo, recai como uma avalanche sobre as lutas dos movimentos dos trabalhadores rurais por reforma agrária, por soberania alimentar, pelo fortalecimento da agricultura de base camponesa e agroecológica e por políticas voltadas ao fortalecimento da agricultura camponesa.

A partir da denominada Revolução Verde na agricultura, iniciada em meados da década de 1950 e revivificada a partir dos anos 1980, com a expansão mundial da concepção de artificialização da agricultura e a ampliação dos contratos de produção entre as empresas capitalistas e as famílias camponesas, introduziu-se a expressão agricultura familiar, outrora de uso consuetudinário aqui e acolá, mas acentuado desde a década de 1990, e consagrada em lei (Brasil, 2006) como expressão formal, porque utilizada por programas e políticas públicas governamentais. ${ }^{9}$

O termo "agricultura familiar" corresponde a múltiplas conotações. Conforme apresentado no Dicionário da Educação do Campo $^{10}$, a agricultura familiar apresenta-se como categoria analítica, segundo significados construídos no campo acadêmico; como categoria de designação politicamente diferenciadora da agricultura patronal e da agricultura camponesa; como termo de mobilização política referenciador da construção de diferenciadas e institucionalizadas adesões a espaços políticos de expressão de interesses legitimados por essa mesma divisão classificatória do setor agropecuário brasileiro (agricultura familiar, agricultura patronal, agricultura camponesa); como termo jurídico que define a amplitude e os limites da afiliação de produtores (agricultores familiares) a serem alcançados pela categorização oficial de usuários reais ou potenciais do Programa Nacional de Fortalecimento da Agricultura Familiar (Pronaf).

Já a expressão "agricultura camponesa" comporta, na sua concepção, a especificidade camponesa e a construção da sua autonomia relativa em relação aos capitais. Incorpora, portanto, 
um diferencial: a perspectiva maior de fortalecimento dos camponeses pela afirmação de seu modo de produzir e de viver, sem com isso negar uma modernidade que se quer camponesa ${ }^{10}$.

É preciso esclarecer que, apesar de muitas vezes o termo agricultura familiar ser entendido como englobando também a agricultura camponesa (como na definição fixada na Lei $n^{\circ} 11.326$, de 24 de julho de 2006, que delimita agricultura familiar baseando-se unicamente no tamanho da propriedade e na mão-de-obra empregada), não é a mesma coisa tratar de agricultura camponesa e de agricultura familiar: ambos os conceitos se referem aos trabalhadores, mas há uma contradição a ser explorada em vista do embate de projetos. Entretanto, este embate não pode ser confundido com o confronto principal: a luta contra o agronegócio.

Conforme apresentado em Caldart et $a l^{10}$ a expressão "agricultura familiar" traz como corolário da sua concepção a ideia de que a possibilidade de crescimento da renda familiar camponesa só poderá ocorrer se houver a integração direta ou indireta da agricultura familiar com as empresas capitalistas, em particular as agroindústrias. Já o polo da agricultura camponesa tende a se opor a esta integração. Assim, o projeto da agricultura camponesa "não tem como ser vitorioso no horizonte da sociedade do capital" ${ }^{\prime 0}$.

Conforme pesquisa divulgada no ano 2000 por INCRA/FAO ${ }^{10}$ e baseada no Censo Agropecuário do IBGE de 1995/96, a chamada agricultura familiar (incluindo a agricultura camponesa) ocupava na época $30,5 \%$ da área e, contando somente com $25 \%$ do financiamento total, foi responsável por $37,9 \%$ da produção nacional. Dado o grande número de estabelecimentos familiares, muitos dos quais com área muito pequena, destinada principalmente para moradia e plantio para subsistência, este percentual é elevado.

Após uma década, o Censo Agropecuário do IBGE de $2006^{11}$ identificou que a agricultura familiar representava $84,4 \%$ dos estabelecimentos agropecuários. No entanto, foi observado decréscimo na área ocupada: de 30,5\% caiu para 24,3\%. Ainda assim, a agricultura familiar foi apontada pelo documento como sendo responsável por parte importante da produção de alimentos consumidos pelos brasileiros, correspondendo: $87 \%$ da produção de mandioca; $70 \%$ da produção de feijão; $46 \%$ da produção de milho; $38 \%$ da produção de café; $34 \%$ da produção de arroz; e 58\% da produção de leite, entre outros.

Em relação ao financiamento, a agricultura familiar segue sendo contemplada com montante expressivamente inferior: enquanto o Plano Agrícola e Pecuário (PAP) 2014/2015 é anunciado com a disponibilização de R \$ 156,1 bilhões ${ }^{12}$ para produtores, o Plano Safra da Agricultura Familiar 2014/2015, que contempla pequenos e médios agricultores, receberá R\$ 24,1 bilhões ${ }^{13}$.

Com menos terra, menos crédito e uso intensivo da força de trabalho, a agricultura familiar vem sendo reconhecida pelas agências governamentais como a principal provedora dos alimentos básicos que abastecem os brasileiros. 
No ano de 2008, foi divulgada pesquisa realizada pelo Instituto do Homem e do Meio Ambiente da Amazônia (Imazon) $)^{14}$ que relacionou o crédito concedido aos pequenos agricultores por meio do Programa Nacional de Fortalecimento daAgricultura Familiar (Pronaf) e o aumento do desmatamento na Amazônia, sugerindo ser a agricultura familiar grande promotora do desmatamento.

Estudos que relacionam degradação ambiental e pobreza também foram realizados pela Organização das Nações Unidas para a Alimentação e para a Agricultura (FAO):"Em todo o mundo, os mais pobres têm menos acesso ao solo e água e são apanhados na armadilha da pobreza das pequenas propriedades com solos de má qualidade e alta vulnerabilidade à sua degradação e à incerteza climática”, observa o relatório.

Cerca de $40 \%$ dos solos degradados no mundo encontram-se em áreas com elevadas taxas de pobreza. Além disso, num sinal de que a degradação é um risco em todos os níveis de rendimento, $30 \%$ dos solos degradados do mundo encontram-se em áreas com níveis moderados de pobreza, enquanto $20 \%$ estão em áreas com baixos índices. ${ }^{15}$

Neste estudo, a FAO sugere que a causa da degradação ambiental seja a pobreza e, a seguir, recomenda:

Melhorar a eficiência do uso da água pela agricultura será fundamental. A maioria dos sistemas de irrigação funciona abaixo de sua capacidade. A combinação de uma melhor gestão da irrigação, o investimento no conhecimento local e na tecnologia moderna e o desenvolvimento da capacitação podem aumentar a eficiência do uso da água. Além disso, práticas agrícolas inovadoras, como a agricultura de conservação, sistemas agroflorestais, integração da produção vegetal e da pecuária e sistemas integrados de irrigação e aquicultura prometem expandir a produção de forma eficiente para garantir a segurança alimentar e combater a pobreza, restringindo ao mesmo tempo os impactos sobre os ecossistemas. ${ }^{16}$

Assim, com o objetivo de aumentar a eficiência da produção agrícola, sugere que os governos realizem "investimento no conhecimento local e na tecnologia moderna" e "desenvolvimento da capacitação".

Contudo, já observamos a intensa articulação do setor do agronegócio no Congresso Nacional - compondo a chamada "bancada ruralista" com campanhas eleitorais amplamente financiadas pelo empresariado ligado ao setor extrativista - e no atual governo brasileiro, assim como o peso das exportações agrícolas (vinculadas a este setor) no crescimento do PIB (Produto Interno Bruto) Nacional.

Notemos que a FAO, em suas recomendações, propõe a integração entre conhecimento local e tecnologia moderna. Para tanto, propõe o desenvolvimento da capacitação dos pequenos agricultores, voltada para esta integração. 
Conforme observado, as recomendações da FAO não privilegiam o setor da agricultura familiar em detrimento do agronegócio. Ao contrário, promovem o aproveitamento dos conhecimentos locais - vinculados à agricultura tradicional, de base familiar - pelo agronegócio para aumentar a eficiência produtiva, ao mesmo tempo em que supostamente reduziriam os conflitos no campo e a degradação ambiental (vinculada à pobreza das pequenas propriedades) ${ }^{16}$.

O documento final da Declaração de Roma ${ }^{17}$ sobre a Segurança Alimentar Mundial afirma que "para reforçar a estabilidade social e impedir o êxodo rural, que muitos países enfrentam, deve-se considerar prioritária também a revitalização das zonas rurais".

Desta forma, a problemática do êxodo rural no Brasil (que se configura prioritariamente com a saída da juventude rural do campo em busca de oportunidades) é enfrentada pelo atual governo com o "incentivo à agricultura familiar". Entretanto, este incentivo não se configura por conceder real importância e autonomia a este setor. Ao contrário, é um incentivo que "expropria" os pequenos agricultores do direito de se reproduzir plenamente por meio de procedimentos tradicionais.

A expropriação primária, original, de grandes massas campesinas ou agrárias, convertidas de boa vontade (atraídas pelas cidades) ou não (expulsas, por razões diversas, de suas terras, ou incapacitadas de manter sua reprodução plena através de procedimentos tradicionais, em geral agrários) permanece e se aprofunda, ao lado de expropriações secundárias, impulsionadas pelo capital-imperialismo contemporâneo. ${ }^{17}$

Fontes $^{18}$ relaciona as expropriações secundárias ao extenso desmantelamento de direitos sociais e trabalhistas que ocorreu nas últimas décadas do século XX e que contou com forte apoio parlamentar, ou seja, mantidas as instituições democráticas, conservados os processos eleitorais e com a sustentação de uma intensa atuação midiática e parlamentar.

Deste modo, expropriações primárias e secundárias são articuladas no meio rural - e sobre as populações do campo - por meio de um intenso trabalho de convencimento (onde projetos educacionais são colocados em disputa) e, principalmente, de coerção.

Neste ponto, é de fundamental importância compreender como a atual fase do capitalismo monopolista se reflete no campo, principalmente sobre os pequenos proprietários rurais. No Brasil, a atuação do capital monopolista no campo levou adiante um processo conhecido como "modernização conservadora"18, que resultou na ampliação da tecnificação da agricultura e incidiu fortemente no "consumo produtivo" de grande número de produtores rurais. Como sabemos, o processo de produzir é também um processo de consumir. Neste sentido, a avançada tecnificação da agricultura, se não leva os agricultores à "privação de matérias-primas”, subjuga-os permanentemente à imposição do uso de sementes geneticamente modificadas e pacotes de químicos indispensáveis para a sua germinação. O agricultor é inserido em uma situação de dependência de uma série de produtos patenteados e comercializados pelos grandes monopólios que vão fornecer 
os insumos para que o plantio e a colheita sejam "bem sucedidos", tais como fertilizantes, adubos e agrotóxicos. A introdução de novas técnicas na agricultura não deixa de repercutir sobre aquelas famílias que se mantêm apegadas aos processos arcaicos de cultivo. A irrigação necessária para as novas espécies cultivadas desorganiza o sistema tradicional de repartição da água. Os agrotóxicos ultrapassam os limites físicos da propriedade de quem os utiliza, contaminando lençóis freáticos e partes de propriedades alheias.

É preciso considerar, também, a repercussão dos elevados custos das inovações técnicas nos orçamentos das famílias. A concessão do crédito rural, muitas vezes, é atrelada à adesão a um "pacote" de insumos químicos. Pelo fato de estes monopólios, atualmente, atuarem ao longo de toda a cadeia da produção rural, observamos os mesmos conglomerados fornecendo não só os insumos químicos, mas também todas as maquinarias necessárias. Assim, para o pequeno agricultor, cobrir as despesas torna-se praticamente a condição básica para que a produção, no ano seguinte, volte a se realizar, pois o endividamento futuro garante a continuidade da produção. Em muitos casos, é possível falar em "escravidão por dívidas", que ampliaria os casos de assalariamento rural, com a liquidação de tantas famílias enquanto produtores tradicionais. Ao mesmo tempo, os camponeses mais abastados, enquanto compradores da capacidade de uso do trabalho alheio, têm de recorrer, cada vez mais, a critérios capitalistas de produtividade ${ }^{19}$.

Se observamos o constante avanço do capital monopolista sobre a esfera da produção e reprodução social da vida no campo, também observamos que este processo não ocorre sem lutas e resistências por parte dos trabalhadores organizados.

Os movimentos da Via Campesina propõem, em vez do agronegócio, a soberania alimentar, que consiste em dar condições dignas para os camponeses produzirem alimentos sadios para a população, com políticas públicas que incentivem a agricultura familiar e o respeito aos conhecimentos tradicionais e à natureza. ${ }^{20}$

Neste cenário, inclui-se a luta por soberania alimentar, que é necessariamente uma luta contra o agronegócio.

As organizações camponesas contrapuseram então ao conceito de segurança alimentar o conceito de soberania alimentar. Partiram do principio de que o alimento não é uma mercadoria, é um direito humano, e a produção e distribuição dos alimentos é uma questão de sobrevivência dos seres humanos, sendo, portanto, uma questão de soberania popular e nacional. Assim, soberania alimentar significa que, além de terem acesso aos alimentos, as populações de cada país têm o direito de produzi-los. [...] E se a produção e a distribuição de alimentos fazem parte da soberania de um povo, elas são inegociáveis e não podem depender de vontades políticas ou práticas conjunturais de governos ou empresas de outros países. [...] Garante também que os direitos de acesso e gestão da terra, dos territórios, das águas, das sementes, do gado e da biodiversidade estejam nas mãos 
daqueles que produzem os alimentos. ${ }^{10}$

Oliveira ${ }^{19}$ retrata o processo de substituição de políticas de soberania alimentar por políticas de segurança alimentar:

No interior desse processo de mundialização e do neoliberalismo, a agricultura que antes baseava-se na produção dos camponeses sustentada por fortes subsídios agrícolas, na revolução verde, na agroquímica, no sistema de estoques governamentais, e tinha na FAO seu órgão mundial, passou a conhecer um profundo processo de mudança. Primeiro, foi a pregação neoliberal contra os subsídios, e consequentemente, contra a agricultura de base familiar camponesa. Segundo, o fim dos estoques governamentais e a substituição das políticas de soberania alimentar pela política de segurança alimentar, sacada da área da saúde pública e alçada para a área das políticas públicas de abastecimento alimentar. Terceiro, a substituição dos estoques governamentais pelos estoques das multinacionais e o mercado como único regulador. Quarto, a criação da Organização Mundial do Comércio - OMC, como órgão mundial de regulação e de decisões mundiais entre os países com contendas comerciais. ${ }^{19}$

Com a substituição do conceito de soberania alimentar pelo de segurança alimentar, o mais importante passa a ser a "garantia do direito humano à alimentação". Esta garantia é de fundamental importância e deve ser buscada continuamente, entretanto, não podemos nos afastar do debate sobre quem produz os alimentos e em quais condições (o que inclui o questionamento das relações de trabalho no campo, o impacto do uso de agrotóxicos sobre os trabalhadores, os debates sobre patrimônio genético, biodiversidade e acesso a sementes não transgênicas e não patenteadas).

A grande questão é que a substituição do conceito de soberania alimentar pelo de segurança alimentar desloca unilateralmente o debate para preocupações relativas à disponibilidade de alimentos, ao acesso à "alimentação adequada" e ao percentual de nutrientes no total de calorias consumidas nos domicílios.

Assim, são feitas pesquisas para identificar o número de domicílios em situação de insegurança alimentar leve, moderada, ou grave e é criado o Conselho Nacional de Segurança Alimentar e Nutricional (CONSEA), que age em âmbito nacional, e os Conselhos Municipais, todos de caráter consultivo e de assessoramento, mas não deliberativo.

O deslocamento do foco das políticas públicas para o conceito de segurança alimentar, ao invés de soberania alimentar, não é apenas uma mudança de palavras, pois no contexto da segurança alimentar prevalece o debate sobre a quantidade de alimentos e, neste embate, o setor do agronegócio tem muitos argumentos a seu favor para, inclusive, se afirmar como modelo ideal para acabar com a fome não só no Brasil, mas no mundo. Ao colocar o foco no "acesso" aos alimentos, é mais fácil flexibilizar a noção de "qualidade" destes alimentos. Além disso, ao deixar de falar em soberania alimentar, admite-se que o patrimônio genético das sementes poderá estar nas mãos 
dos monopólios e que os pequenos agricultores, se quiserem plantar, deverão estar subordinados a estes monopólios.

\section{O PROGRAMA DE EDUCAÇÃO AMBIENTAL E AGRICULTURA FAMILIAR (PEAAF) E O DISCURSO PEDAGÓGICO DA PARTICIPAÇÃO}

O PEAAF é um programa educacional desenvolvido pelo Ministério do Meio Ambiente a partir de reivindicações de trabalhadores rurais organizados no Grito da Terra $2009^{21}$.

Este programa educacional está em construção e debate desde $2009^{22}$, entretanto, só foi instituído formalmente por meio de portaria do Ministério do Meio Ambiente em maio de 2012.

A pauta reivindicativa do Grito da Terra 2009 - que serviu de "pontapé inicial” para a criação do PEAAF - exige um projeto de educação ambiental que seja desenvolvido pela Confederação Nacional dos Trabalhadores na Agricultura (Contag), em conjunto com alguns Ministérios, para atender às necessidades dos trabalhadores. Entretanto, na portaria n ${ }^{\circ} 169$, de 23 de maio de 2012, que institui o PEAAF, não há referência a nenhuma organização de trabalhadores rurais ou "representantes da sociedade civil" na elaboração do programa.

Assim, apesar de ter sido reivindicado por trabalhadores rurais, os trabalhadores são excluídos do processo decisório e o programa é elaborado de forma que inclua somente representantes do "Estado em sentido estrito".

Os objetivos do PEAAF são:

Contribuir para o desenvolvimento rural sustentável e a regularização ambiental das propriedades rurais voltados para a agricultura familiar, tendo como referência a agroecologia e práticas produtivas sustentáveis, por meio de processos educacionais críticos, participativos e dialógicos que promovam a formação, capacitação, comunicação e mobilização social. ${ }^{23}$

De acordo com a análise dos objetivos do PEAAF, notamos que a educação é tratada como meio para alcançar o referido "desenvolvimento rural sustentável”, que, por sua vez, está relacionado com a "regularização ambiental" das propriedades agrícolas e com a "agroecologia e práticas produtivas sustentáveis". Assim, processos educacionais críticos, participativos e dialógicos, que promovam a formação, capacitação, comunicação e mobilização social seriam o meio para alcançar o referido “desenvolvimento rural sustentável”.

O PEAAF, de acordo com os próprios dirigentes do governo envolvidos com a sua implementação, é assumido enquanto um programa sem muitos recursos (tanto de pessoas para trabalhar quanto recursos financeiros) e que precisa de "parcerias" para funcionar. Com as características de ser um programa educacional "flexível”, de estar "em permanente processo de construção", ao ser 
$60 / /$

implementado nos diversos estados brasileiros - processo que é realizado através de "acordo de cooperação técnica" entre o Ministério do Meio Ambiente e os governos estaduais -, ainda tende a colaborar para fortalecer as oligarquias agrárias locais (a pequena política local).

A dinâmica política que observamos no Congresso Nacional, de intensa articulação de ruralistas e empresários lutando pelos seus interesses, é reproduzida na constituição dos governos estaduais e municipais, principalmente naqueles estados que oferecem abundância de recursos naturais e força de trabalho a serem explorados.

Assim, em cada Estado onde é implementado, o PEAAF “assume a cara do lugar", se adaptando à dinâmica da pequena política local e contribuindo para enfraquecer o debate acerca da grande politica.

A grande política compreende as questões ligadas à fundação de novos Estados, à luta pela destruição, pela defesa, pela conservação de determinadas estruturas orgânicas econômico-sociais. A pequena política compreende as questões parciais e cotidianas que se apresentam no interior de uma estrutura já estabelecida em decorrência de lutas pela predominância entre as diversas frações de uma mesma classe política (política do dia a dia, política parlamentar, de corredor, de intrigas). Portanto, é grande política tentar excluir a grande política do âmbito interno da vida estatal e reduzir tudo à pequena política. ${ }^{23}$

O que fica de fora do debate no âmbito do PEAAF é a própria função da educação ambiental em um contexto onde a luta de classes se apresenta de forma tão explícita como é o caso do meio rural. Uma educação ambiental verdadeiramente crítica e transformadora deveria buscar proporcionar a compreensão acerca das lutas historicamente travadas tanto pela destruição quanto pela conservação de determinadas estruturas econômico-sociais.

Ao contrário, o que observamos sobre a educação ambiental promovida pelo Ministério do Meio Ambiente e voltada para a agricultura familiar é o seu caráter pragmático, com ênfase no esclarecimento das legislações ambientais, no enquadramento do agricultor nos programas de regularização ambiental da propriedade rural, na difusão de "iniciativas exitosas" e na promoção de "parcerias". Uma educação ambiental que não promove a leitura crítica da realidade visando à sua transformação e que se nega a debater os impactos socioambientais de programas do Governo Federal como o Programa de Aceleração do Crescimento (PAC) e as alterações concretas promovidas pela reforma do Código Florestal (Lei n.12.651/12), que tornaram o processo de recuperação de áreas degradadas (processos longos e incertos, em alguns casos) passível de ter seu valor especulado no mercado, fazendo com que a "regularização ambiental" expresse valores unicamente mercantis.

Ao se auto referenciar enquanto um programa educacional crítico e participativo, o PEAAF ressignifica o conceito de participação, de forma que seja priorizada a "participação" (sem poderes concretos de decisão) de indivíduos isolados, sem filiações ideológicas explícitas, fragmentados 
em diversos grupos, em oposição à real participação da massa oprimida organizada, com pautas concretas e unificadas.

Um Programa de Educação Ambiental para Agricultura Familiar promovido pelo Estado em sua atual configuração - com extrema vinculação com a perspectiva do agronegócio - tende a difundir as bases ideológicas necessárias para a hegemonia de um conceito de agricultura familiar que seja mais favorável ao capital, por meio de um "ideário ambiental" de forte característica conciliadora no "mascaramento" dos conflitos sociais no campo e pragmática ao promover as reformulações necessárias para que pequenos agricultores sirvam melhor ao capital.

Trata-se, assim, de subordinar a função social da educação de forma controlada para responder às demandas do capital, criando um falso consenso entre trabalhadores rurais e empresários do agronegócio mundializado sob o discurso da "parceria" entre as classes.

\section{O PROSAVANA EM MOÇAMBIQUE}

O Programa Prosavana resulta de um acordo firmado, em 2009, entre os governos de Brasil, Japão e Moçambique e tem como instituições executoras a Empresa Brasileira de Pesquisa Agropecuária - Embrapa; Agência Japonesa de Cooperação - JICA e o Instituto de Investigação Agrária de Moçambique - IIAM.

Concebido como um Programa de Desenvolvimento Agrícola e Rural para o Corredor de Nacala, em Moçambique, o Prosavana-JBM tem como objetivo melhorar a competitividade do setor rural da região, tanto em matéria de segurança alimentar a partir da organização e do aumento da produtividade no âmbito da agricultura familiar, como na geração de excedentes exportáveis a partir do apoio técnico à agricultura orientada para o agronegócio. ${ }^{24}$

De acordo com Classen ${ }^{25}$, o programa Prosavana não foi, desde o seu início, concebido em conjunto com os habitantes locais de Moçambique e não foi pensado com o objetivo de satisfazer as necessidades locais. Em vez disso, o programa teve início no ano 2000, com a criação de um quadro para a Cooperação inter-governamental Japão-Brasil (Parceria Programa-JBPP). Segundo Classen $^{26}$, o Prosavana foi concebido como uma forma de os governos de Japão e Brasil trabalharem em conjunto para alcançarem a reforma da ONU; participarem das novas estruturas políticas/ econômicas globais como BRICS e G20; e promoverem conjuntamente a produção/extração de commodities.

Outros autores ${ }^{26}$ apontam que o envolvimento do Brasil neste acordo de cooperação internacional faz parte de um projeto de incentivo à expansão de empresas brasileiras, especialmente para América Latina e África, por parte do Banco Nacional de Desenvolvimento Econômico e Social (BNDES). Tal argumento encontra fundamento quando observamos a presença de quatro grandes empresas brasileiras em Moçambique (Vale, Andrade Gutierrez, Camargo Corrêa e Odebrecht) realizando obras de infraestrutura e exploração de minérios. 
Os documentos oficiais elaborados no âmbito do Prosavana ${ }^{25}$, ao contrário, afirmam que o programa foi desenvolvido em função de necessidades que partiram da população local, como a necessidade de estabelecer um modelo regional de planejamento participativo no âmbito da agricultura familiar.

Nesta direção, o Prosavana-TEC foi desenvolvido em função das seguintes necessidades: i) construir e consolidar uma base de conhecimentos sobre os recursos naturais disponíveis para uso agrícola e seus usos sustentáveis; ii) fortalecer e consolidar a infraestrutura física e institucional do aparato de pesquisa regional; iii) estabelecer um modelo regional de planejamento participativo no âmbito da agricultura familiar; iv) estabelecer um modelo de gestão dos recursos humanos visando a ampliação dos quadros técnicos do IIAM, incluindo a capacitação e o treinamento e pessoal; e v) promover ações de comunicação para uma rápida disseminação junto aos agricultores das tecnologias recomendadas. ${ }^{25}$

Classen $^{26}$, que discutiu as mudanças discursivas no Prosavana e analisou os seus antecedentes, evidencia que a falta de prestação de contas e de transparência para com os cidadãos locais têm persistido ao longo do tempo.

Embora os planejadores e promotores do programa Prosavana tenham conseguido levantar fundos públicos (impostos), sublinhando palavras como "falta", "não utilizado", "baixa produtividade", "pobreza", "escassez de alimentos", eles estavam com base apenas em observações de dados de nível macro, suposições e imagens, sem qualquer investigação real no terreno, nem discussões com aqueles que estão vivendo lá. ${ }^{26}$

O documento do Prosavana também tende a depreciar a atual organização rural da região fortemente baseada na agricultura de subsistência -, classificando-a de "pouco produtiva" em comparação com o modelo brasileiro de agricultura:

Apenas 29\% dos agricultores moçambicanos produzem algum excedente para o mercado, e os níveis de produção e de produtividade agrícolas são extremamente baixos. Uma comparação com as produtividades obtidas no Brasil para essas culturas permite concluir que os rendimentos brasileiros são mais elevados de seis até dez vezes que os rendimentos obtidos em Moçambique. ${ }^{25}$

Em termos de infraestrutura, o Prosavana prevê a estruturação de "centros integrados de investigação agrária", equipados com laboratórios e unidades de "beneficiamento" de sementes genéticas e básicas, dispondo de "recursos humanos capazes de planejar, coordenar e executar projetos de pesquisa agropecuária".

Em termos de capacitação e treinamento de recursos humanos, a ideia é romper os problemas de internalização dos sistemas de produção a serem estudados e recomendados e relativos tanto aos diferentes idiomas falados no campo, como no que se refere às atitudes e comportamentos sociais segundo as diferentes etnias e estágios de conhecimentos em agricultura e pecuária. Neste caso, // Tempus, actas de saúde colet, Brasília, 8(2), 47-67, jun, 2014.

ISSN 1982-8829 
é que se pretende envolver instituições e organizações locais na execução do projeto, treinar seus quadros no Brasil e em Moçambique, e formar uma equipe de pelo menos 150 multiplicadores capazes de ensinarem e disseminarem na região novas técnicas de gerenciamento do uso de recursos naturais para uso agrícola; de multiplicação, beneficiamento e comércio de sementes; de gestão da pesquisa, planejamento participativo e de difusão de tecnologias; e do uso de modelos de decisão para o gerenciamento da produção, processamento e comércio da produção agrícola; entre outros. 25

Percebemos que o Prosavana carrega em seu discurso a ideia de educação enquanto uma ferramenta voltada unicamente para "capacitação" e "treinamento" de pessoas - vistas como "recursos humanos" -, com o objetivo de facilitar a chamada "internalização" das recomendações, em um processo explicitamente de fora para dentro. A previsão de formação de "multiplicadores" reforça esta ideia, afirmando que estes indivíduos terão a função de disseminar "novas técnicas de gerenciamento do uso de recursos naturais", desconsiderando as técnicas tradicionais locais. Ao mesmo tempo, o documento fala de "planejamento participativo".

Nestes "Centros Integrados" também está prevista a criação de um módulo de "Educação Ambiental em Agricultura". Entretanto, o projeto não fornece maiores detalhes sobre os objetivos educacionais deste módulo.

Conforme observamos, o discurso pedagógico da "parceria" encontra-se presente também no Programa Prosavana. Assim como no PEAAF, a parceria aqui é enfatizada como sendo uma cooperação para o desenvolvimento mútuo, em que as duas partes se beneficiariam com a "troca de experiências" e "oportunidades comuns de aprendizado".

O lado brasileiro fala sobre os benefícios dos três países. Três países que têm diferentes pontos fortes, o que torna a partilha do trabalho fácil e clara. O Brasil vai produzir, o Japão vai distribuir e Moçambique vai estabelecer bases sólidas para os investimentos. O Japão, que no passado auxiliou o crescimento da agricultura brasileira, vai cooperar com o Brasil para auxiliar o desenvolvimento da agricultura em Moçambique. É importante que todos tenham benefícios envolvidos a partir desta ação. (Organização Japonesa de Comércio Exterior) ${ }^{26}$

O que não fica claro é de que forma os agricultores moçambicanos se beneficiarão com estes "investimentos". Devido à insuficiência de informações e à falta de transparência do processo de implantação do Prosavana, camponeses moçambicanos têm se unido a movimentos rurais brasileiros na denúncia deste projeto.

Após uma análise profunda do ProSavana, Nós camponesas e camponeses, concluímos que:

- O ProSavana é resultado de uma política que vem do topo para a base, sem no entanto levar em consideração as demandas, sonhos e anseios da base, particularmente dos camponeses do Corredor de Nacala; 
- Condenamos veementemente qualquer iniciativa que preconize o reassentamento de comunidades e expropriação de terra dos camponeses, para dar lugar à mega projectos agrícolas de produção de monoculturas (soja, cana-de-açúcar, algodão etc.);

- Condenamos a vinda em massa de agricultores brasileiros que se dedicam ao agronegócio, transformando camponesas e camponeses moçambicanos em seus empregados e em trabalhadores rurais;

Notamos com enorme preocupação que o ProSavana demanda milhões de hectares de terra ao longo do Corredor de Nacala, porém a realidade local mostra a falta de disponibilidade dessas extensões de terra, visto que a mesma é usada por camponeses com recurso à técnica de pousio. ${ }^{27}$

\section{CONCLUSÃO}

Neste trabalho, buscamos apontar que o campo da Educação vem sendo historicamente disputado como importante ferramenta de convencimento e construção de falsos consensos, conformando a massa de trabalhadores ao projeto de desenvolvimento focado no extrativismo e na exploração dos trabalhadores, da terra e dos demais recursos naturais. Desta forma, a perspectiva da formação para a emancipação humana e o desenvolvimento pleno das capacidades individuais e coletivas tem se afastado do campo da educação, dando lugar à "capacitação" para que o trabalhador consiga operacionalizar ferramentas e técnicas, se tornando um "multiplicador" deste "conhecimento".

É neste sentido que se insere a observada "pedagogia da participação", como meio de angariar o consentimento ativo dos trabalhadores para um modelo que lhes é imposto e que os prejudica. Nesta "pedagogia", o termo "parceria" é ressaltado como algo intrinsecamente positivo, desconsiderando que uma "parceria" entre desiguais tende a obscurecer processos de subordinação.

Ao mesmo tempo, a "pedagogia da participação" desvia o foco das tensões sociais no meio rural, fundamentadas na incompatibilidade estrutural do modelo do agronegócio com o modelo de agricultura camponesa e nas crescentes expropriações promovidas pelo capital no campo. $\mathrm{O}$ fato de "participar" destas políticas não garante mecanismos em que o trabalhador possa reverter o atual quadro de expropriação.

Ao apresentar o caso do Prosavana em Moçambique não buscamos realizar uma análise aprofundada acerca das contradições deste programa. Para tanto, nos faltariam mais elementos de análise, visto que ele se encontra em fase inicial de implantação.

Entretanto, ao olhar para este caso a partir da análise do PEAAF, podemos observar alguns pontos estruturais em comum, como o discurso da "parceria" e da "participação", acompanhado da ofensiva do capital no campo, sob a figura do agronegócio. 
Até o presente momento, foi possível observar que, no caso do Prosavana em Moçambique, a "participação" aparece como uma promessa remota, que tem apresentado poucos indícios de que venha a se concretizar.

\section{REFERÊNCIAS}

OECD. Políticas Agrícolas : Monitoração e Avaliação 2013 dos Países da OCDE e das Economias Emergentes. Disponível em < http://www.oecd.org/tad/agricultural-policies/AgMon_2013_Brazil_ PRT.pdf $>$.

2 O Índice de Gini, criado pelo matemático italiano Conrado Gini, é um instrumento para medir o grau de concentração de renda em determinado grupo. Ele aponta a diferença entre os rendimentos dos mais pobres e dos mais ricos. Numericamente, varia de zero a um (alguns apresentam de zero a cem). O valor zero representa a situação de igualdade, ou seja, todos têm a mesma renda. O valor um (ou cem) está no extremo oposto, isto é, uma só pessoa detém toda a riqueza.

3 Ministério da Agricultura. Disponível em www.agricultura.gov.br/politica-agricola/ noticias/2012/01/produtividade-agricola-do-brasil-cresce-mais-do-que-a-mundial.

4 Davis JH, Goldeberg R. A Concept of Agribusiness. Boston: Havard University; 1957.

5 Associação Brasileira do Agronegócio. Disponível em < $\underline{\text { http://www.abag.com.br/ }>}$

6 Accioly I B. Anti-Ecologismo no Congresso Nacional: o meio ambiente representado na Câmara dos Deputados e no Senado Federal. Monografia de conclusão Pós-Graduação "lato-sensu" Educação Ambiental para Sociedades Sustentáveis. Rio de Janeiro: PUC-Rio/Coordenação Central de Extensão; 2011.

7 Instituto Brasileiro de Geografia e Estatística. Disponível em http://saladeimprensa.ibge. gov.br/noticias? view=noticia\&id=1\&busca=1\&idnoticia $=2306$.

8 Osorio J. Padrão de reprodução do capital: uma proposta teórica. In: Ferreira, Osorio, Luce (Orgs.). Padrão de reprodução do capital: contribuições da teoria marxista da dependência. São Paulo: Boitempo; 2012.

9 Caldart RS, Pereira IB, Alentejano P, Frigotto G. (Orgs.). Dicionário da educação do campo. Rio de Janeiro/São Paulo: Escola Politécnica de Saúde Joaquim Venâncio, Expressão Popular; 2012 .

10 Projeto de Cooperação Técnica INCRA/FAO. Novo Retrato da Agricultura Familiar: O Brasil Redescoberto. Brasília. 2000. 
11 Instituto Brasileiro de Geografia e Estatística - IBGE. Censo agropecuário 2006. Disponível em < http://biblioteca.ibge.gov.br/visualizacao/periodicos/50/agro_2006_ agricultura_familiar.pdf $>$.

12 Portal Brasil. Disponível em http://www.brasil.gov.br/economia-e-emprego/2014/05/ plano-safra-2014-2015-dispobiliza-r-1560-bi-para-produtores.

13 Agência de Notícias do Acre. Disponível em http://www.agencia.ac.gov.br/noticias/acre/ agricultura-familiar-tera-r-241-bilhoes-para-producao-de-20142015.

14 Instituto do Homem e do Meio Ambiente da Amazônia. Disponível em < http://www. estadao.com.br/noticias/geral,credito-oficial-estimula-desmatamento-indica-estudo,115464,0. $\mathrm{htm}>$.

15 FAO. Disponível em < https://www.fao.org.br/edsaasa.asp $>$.

16 Declaração de Roma Sobre a Segurança Alimentar Mundial e Plano de Acção da Cimeira Mundial da Alimentação. "Conflitos, terrorismo, corrupção e degradação do meio ambiente também contribuem significativamente para a insegurança alimentar”.1996. Disponível em <http:/www.fao.org/docrep/003/w3613p/w3613p00.htm>

17 Fontes V. O Brasil e o capital-imperialismo: teoria e história. Rio de Janeiro: EPSJV/ Editora UFRJ; 2010.

18 Oliveira A U. Agricultura e indústria no Brasil. Campo-território: Revista de Geografia Agrária, 5(10), 5-64; 2010.

19 Bernardo J. Economia dos conflitos sociais. São Paulo: Expressão Popular; 2009.

20 Movimento dos Trabalhadores Sem Terra. Disponível em: < $\underline{\text { http://www.mst.org.br/content/ }}$ campesina-acaba-com-festa-da-hipocrisia-da-cna-e-denuncia-recorde-de-agrot $\% \mathrm{C} 3 \% \mathrm{~B} 3 \times \mathrm{xicos}>$. Acesso em outubro de 2012.

21 Movimento reivindicativo assinado por CONTAG, FETAG e STTR.

22 Ministério do Meio Ambiente. Disponível em<http://www.mma.gov.br/educacaoambiental/formacao-de-educadores/programa-de-educa $\% \mathrm{C} 3 \% \mathrm{~A} 7 \% \mathrm{C} 3 \% \mathrm{~A} 30$-ambiental-eagricultura-familiar-peaaf $>$.

23 Gramsci A. Cadernos do cárcere. Vol.3. Rio de Janeiro: Civilização Brasileira; 2011.

24 Agência Brasileira de Cooperação/ EMBRAPA. JBPP/PCJ/008-JBM. ProSAVANA-

// Tempus, actas de saúde colet, Brasília, 8(2), 47-67, jun, 2014. 
TEC. 2011. Disponível em <http://www.undp.org.br/Extranet/SAP\%20FILES/MM/2011/14740/ PROSAVANA-TEC\%20-\%20RESUMO\%20EXECUTIVO.pdf $>$

25 Classen S F. Analysis of the Discourse and Background of the ProSAVANA Programme in Mozambique - focusing on Japan's role. Tokyo. 2013. Disponível em $<$ http://www.open. ac.uk/technology/mozambique/sites/www.open.ac.uk.technology.mozambique/files/files/ ProSavana\%20Analysis\%20based\%20on\%20Japanese\%20source\%20(FUNADA2013).pdf>.

26 Schlesinger S (Org.). Cooperação e investimentos do Brasil na África: o caso do Prosavana em Moçambique. Maputo: Federação de Órgãos para Assistência Social e Educacional (FASE); 2013.

27 União Nacional de Camponeses. Nampula, Moçambique. 11 de Outubro de 2012. Disponível em < http://www.contag.org.br/arquivos/portal/file/site/Prosavana.pdf>.

Artigo apresentado em 03/03/14 Artigo aprovado em 26/05/14 Artigo publicado no sistema em 29/06/14 